\title{
Induction of Renal Growth and Injury in the Intact Rat Kidney by Dietary Deficiency of Antioxidants
}

\author{
Karl A. Nath and Abdulla K. Salahudeen \\ with the technical assistance of Anthony J. Croatt and Stefan M. Kren \\ Department of Medicine, University of Minnesota, Minneapolis, Minnesota 55455
}

\begin{abstract}
We report induction of renal growth and injury in the intact rat kidney using a diet deficient in vitamin $\mathbf{E}$ and selenium. This diet was imposed in 3-wk-old male weanling rats, and after 9 wk, enhancement of growth, characterized by increased wet weight, dry weight, protein content, and DNA content appeared. Morphometric analyses revealed increased kidney volume, tubular epithelial volume, and mean glomerular volume. There were no differences in nephron number. The animals on the deficient diet displayed increased urinary protein excretion at 9 wk. Renal injury was also characterized by an interstitial cellular infiltrate and diminutions in glomerular filtration rate. Enhanced growth and injury were antedated by increased renal ammoniagenesis. The deficient diet did not induce metabolic acidosis, potassium depletion, glucose intolerance, or elevated plasma amino acid concentration. Enhancement of renal growth and ammoniagenesis by the deficient diet was not suppressible by chronic alkali therapy. Stimulation of renal growth could not be ascribed to increased intrarenal iron, induction of ornithine decarboxylase, or alterations in glomerular hemodynamics. Stimulation of renal ammoniagenesis by dietary deficiency of antioxidants is a novel finding, as is induction of growth and injury. We suggest that increased renal ammoniagenesis contributes to induction of renal growth and injury. (J. Clin. Invest. 1990. 86:1179-1192.) Key words: ammonia oxidants $\bullet$ growth $\bullet$ injury $\bullet$ kidney
\end{abstract}

\section{Introduction}

The recognition that renal growth occurs concomitantly with, and may be a prerequisite for, the development of renal injury in several disease models has contributed to the resurgence of interest in the study of renal growth (1). Several dietary manipulations stimulate renal growth and provoke renal damage in the intact kidney including increased protein intake and potassium deprivation (2-4). Sustained increments in dietary protein intake stimulate hypertrophy of the intact kidney while concomitantly inducing renal injury as demonstrated by in-

An abstract of this work was presented at the American Society of Nephrology meeting, 1988 and the First International Workshop on Renal Growth, London, 1989 and has been published (1989. Kidney Int. 35:434).

Address reprint requests to Dr. Nath, Box 736, UMHC, 516 Delaware Street SE, Minneapolis, MN 55455.

Received for publication 23 October 1989 and in revised form 4 April 1990.

J. Clin. Invest.

(C) The American Society for Clinical Investigation, Inc.

$0021-9738 / 90 / 11 / 1179 / 14 \$ 2.00$

Volume 86, October 1990, 1179-1192 creased rates of urinary protein excretion and greater histologic scores for glomerular sclerosis (2). Potassium deprivation promotes overall nephronal growth with a striking adenomatous hyperplastic response in the distal nephron (4). That the enlarged kidney in potassium deficiency is also injured is indicated by vacuolization along the tubular epithelium, a fibrocellular interstitial infiltrate, increased rates of urinary protein excretion, and diminished glomerular filtration and plasma flow rates $(3,4)$. Although the mechanisms underlying the renal effects of these dietary manipulations remain elusive, such dietary intervention provides insights into the biology of renal growth in general and the interaction of renal growth and injury in particular. Moreover, these dietary manipulations, imposed in the setting of experimental renal injury, have contributed to our understanding of the progressive nature of chronic renal injury $(1,5-7)$.

We report another dietary manipulation that induces renal growth and damage in the intact, nonmanipulated, rat kidney and concomitantly reduces overall somatic growth. This dietary manipulation consists of sustained deficiency of antioxidants, vitamin $\mathrm{E}$ and selenium. The oxidant scavenging capabilities of these dietary sources are derived in the following manner (8-10). Selenium is a cofactor for glutathione peroxidase, the enzyme that detoxifies organic and hydrogen peroxides (9). Selenium deficiency impairs the degradation of hydrogen peroxide and other lipid peroxides by glutathione peroxidase and thus promotes the accumulation of reactive oxygen intermediates (9). Additionally, selenium deficiency promotes vitamin $\mathrm{E}$ deficiency by increasing the degradation of vitamin $E(11,12)$. Residing in plasma and intracellular membranes, vitamin $E$ is the major, lipid-soluble substance that interrupts initiation and/or propagation of free radical chain reactions that impose oxidant stress $(10,13)$. A prooxidant state is thus effected by combined dietary deficiency of selenium and vitamin E: selenium deficiency accounts for impaired removal of reactive oxygen intermediates while vitamin E deficiency promotes the attendant oxidant effects of these molecular species $(8,13,14)$. We examined the effect of this dietary manipulation on the growth of the intact rat kidney and observed enhancement of renal growth and induction of renal injury. We explored multiple pathways through which dietary deficiency of antioxidants exerts these renal effects. We noted markedly increased rates of renal ammoniagenesis before the appearance of enhanced renal growth and injury, and we suggest that such augmented rates of ammonia production underlie, at least in part, the renal effects exerted by dietary deficiency of selenium and vitamin $\mathrm{E}$.

\section{Methods}

Composition of the diets

Male Sprague-Dawley rats weaned at 3 wk of age and weighing $\sim 40-50 \mathrm{~g}$ were commenced on a diet deficient in vitamin $\mathrm{E}$ and 
selenium or the control diet (diets TD84253 and TD84254, respectively, Teklad, Madison, WI). The exact dietary constituents are shown in Table I. The selenium content of the deficient diet was $<0.025$ parts per million and the control diet contained 0.25 parts per million of selenium. Vitamin E deficiency was achieved in the deficient diet by stripping the fat source, lard, of $\alpha$-tocopherol; the control diet was supplemented with $d l-\alpha$-tocopheryl acetate $(1,000 \mathrm{U} / \mathrm{g}$ at a rate of 0.05 $\mathrm{g} / \mathrm{kg}$ ). These diets were isocaloric and had identical electrolyte and mineral content. The protein content was $\sim 15 \%$ protein by weight and was provided by torula yeast $(30 \mathrm{~g} / \mathrm{kg})$. This source of protein was employed since it contains relatively low levels of selenium. Rats were maintained on these diets and tap water ad libitum for up to $14 \mathrm{wk}$ after weaning. Weekly measurements of food intake were undertaken.

\section{Clearance and micropuncture studies}

Whole-kidney hemodynamic and glomerular hemodynamic measurements were undertaken $6 \mathrm{wk}$ after dietary assignment, i.e., just before the appearance of renal enlargement in rats on the deficient diets, and whole-kidney hemodynamic measurements were again undertaken after renal growth and injury were well established in the rats on the deficient diets, i.e., $11 \mathrm{wk}$ after dietary assignment. On the morning of the study, rats were anesthetized with Inactin $(100 \mathrm{mg} / \mathrm{kg}$ body weight; B. Y. K. Gulden, Konstanz, FRG) and placed on a temperature-regulated table with maintenance of the body temperature between 37 and $38^{\circ} \mathrm{C}(15)$. A PE-50 catheter was inserted into the left femoral artery for blood sampling and for blood pressure monitoring via a pressure transducer (model P23DB, Statham Instruments, Oxnard, CA) and connected to a duograph recorder (model 1CT-2H, Gilson Medical Electronics, Inc., Middleton, WI). After femoral cannulation, a blood sample was taken for the measurement of hematocrit and total plasma protein. Hematocrit was determined by a microcapillary hematocrit reader (International Equipment Co., Needham, MA) and total plasma protein was measured by refractometry. A tracheal catheter, fashioned from PE-240 tubing, was inserted and both external jugular veins were catheterized with PE-50 tubing. A PE-10 catheter was inserted into the left ureter and urine volume was determined gravimetrically. To replace surgical losses and maintain constancy of the initial hematocrit, rats were infused with isooncotic rat plasma in the following manner: $1 \%$ of body weight was administered over $30 \mathrm{~min}$ and an infusion rate of $0.5 \mathrm{ml} / \mathrm{min}$ was maintained throughout the study (15). To determine glomerular filtration rate (GFR) and single nephron (SN)GFR normal saline containing [methoxy- ${ }^{3} \mathrm{H}$ ]inulin $(100 \mu \mathrm{C} / \mathrm{ml})$ was infused at a rate of $1.2 \mathrm{ml} / \mathrm{h}$ after an initial bolus dose of $0.5 \mathrm{ml}$ administered over $5 \mathrm{~min}$. The left kidney in the deficient and control

Table I. Details of the Diets

\begin{tabular}{lrc}
\hline \multicolumn{3}{c}{ Deficient diet (Teklad diet TD84253) } \\
\hline & $g / k g$ & $\%$ \\
Torula Yeast & 300 & 30 \\
Sucrose & 595 & 59.5 \\
Lard, Tocopherol-stripped & 50 & 5.0 \\
dl-Methionine & 3 & 0.3 \\
Mineral mix (Hubbell-Mendel-Wakeman) & 50 & 5.0 \\
Teklad vitamin mix & 1 & 0.1 \\
Choline dihydrogen citrate & 1 & 0.1
\end{tabular}

Control diet (Teklad diet TD84254)

The deficient diet is modified in the following way to produce the control diet:

(a) Sodium-selenite sucrose mix $\left(0.0445 \% \mathrm{Na}_{2} \mathrm{SeO}_{3}\right)$ is added at a rate of $1.24 \mathrm{~g} / \mathrm{kg}$ providing $0.25 \mathrm{ppm}$ selenium.

(b) Sucrose is decreased to $594 \mathrm{~g} / \mathrm{kg}$.

(c) $d \mathrm{l}-\alpha$-Tocopheryl acetate $1,000 \mathrm{U} / \mathrm{g}$ is added at a rate of $0.05 \mathrm{~g} / \mathrm{kg}$. animals was set up for micropuncture studies as previously described (15). A 23-gauge needle connected to a tuberculin syringe by PE-50 tubing was introduced in the left renal vein and advanced so that the tip of the needle was positioned at the hilum of the kidney. Filtration fraction was calculated from the extraction of inulin across the kidney. Approximately $30 \mathrm{~min}$ after starting the radioactive infusion, two clearance periods were performed. At the midpoint of each collection period, a $100-\mu \mathrm{l}$ sample of arterial blood was drawn from the femoral artery and immediately thereafter a sample of renal venous blood was taken. Before and after the midpoint of the clearance period, time collections of proximal tubular fluid were obtained by standard micropuncture techniques from the proximal tubular surface convolutions. A minimum of three collections of tubular fluid was performed for each determination of SNGFR in a rat. Hydraulic pressure measurements were made in cortical tubules and in the efferent arterioles by the servo-null micropipette technique. Glomerular capillary pressure was measured by the stop-flow methodology using the servo-null micropipette technique. Values of proximal tubular and efferent arteriolar pressures and glomerular capillary pressures were the means of at least three determinations. The details of the calculations employed to determine the glomerular hemodynamic profile are given in previous publications (15).

\section{Determination of nephron number}

Measurement of nephron number was performed using the method of Damadian et al. (16) as modified by Kaufman et al. (17) for the rat. Upon completion of the clearance study the carotid artery was catheterized with PE-50 tubing and $1 \mathrm{ml}$ of colloidal carbon was injected to serve as a marker for glomeruli. The kidney was excised, the capsule and surrounding fascia were stripped off, and the kidney was placed in $50 \%$ hydrochloric acid in a glass scintillation vial for $\sim 3 \mathrm{~h}$. The acid was aspirated and the kidney was kept in distilled water overnight at $4^{\circ} \mathrm{C}$. The kidney was then macerated with a rubber policeman in a volume of $20 \mathrm{ml}$ of distilled water and the contents were repeatedly aspirated, sequentially, through $35-\mathrm{ml}$ syringes attached to $5-\mathrm{cm}$ lengths of PE-190, PE-90, and PE-50 tubing. The contents were then mechanically stirred for $1 \mathrm{~h}$. During stirring, aliquots of $50 \mu \mathrm{l}$ of the homogenate, sampled from varying levels of the homogenate, were streaked onto filter paper (Whatman, Inc., Clifton, NJ) and the number of glomeruli were counted under a microscope at a magnification of 50. Nephron number for each kidney represented the mean counts from 10 aliquots from each kidney homogenate.

Nephron number was also determined from the morphometric data obtained in rats studied at $14 \mathrm{wk}$. Total glomerular volume and mean glomerular volumes were independently measured by morphometric techniques in animals maintained on these diets for $14 \mathrm{wk}$. Nephron number was determined as the quotient of total glomerular volume and mean glomerular volume.

\section{Morphometry}

All morphometric analyses were performed in kidneys fixed by perfusion at mean arterial pressure of the rat with $1.25 \%$ glutaraldehyde in

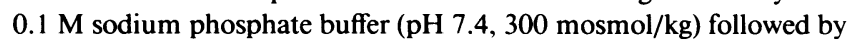
immersion in fixative for $1 \mathrm{~h}$. The perfused kidney was weighed, the length was measured with a vernier caliper to $0.1 \mathrm{~mm}$ (vernier type 6914, Science Ware Pequanock, NJ), and the kidney was sliced into coronal sections using a stainless steel tissue slicer in which razor blades were aligned in a parallel fashion and spaced $2 \mathrm{~mm}$ apart. All slices except the terminal slice lacking the corresponding right side cut surface were placed into cassettes with the right side up and embedded in paraffin, and sections were cut, $5 \mu \mathrm{m}$ thick, and mounted onto a glass slide. All morphometric analyses were performed in a blinded fashion. Our morphometric analyses were based on the method of point counting. The principles and applications of point counting are discussed in detail by Weibel (18) and Pfaller et al. (19).

Measurement of kidney volume. We measured kidney volume using the Cavalieri principle as adapted by Gundersen and Jensen (20). In essence, the Cavalieri principle states that the volume of a particle is the product of the mean thickness of slices made through the particle 
and the sum of the cross-sectional areas of these serial slices through the particle. In their application of the Cavalieri principle to the kidney, Gundersen and Jensen (20) have shown that bias is minimized by omitting the cross-sectional area of the largest profile in the calculation of kidney volume. The profiles of the slices were traced onto millimeter graph paper (each square is $1 \mathrm{~mm}^{2}$ ) and the number of points encompassed by each profile were counted. The number of points gives the cross-sectional area of the slice in square millimeters. As demonstrated by Gundersen and Jensen (20), the volume of the kidney in cubic millimeters is determined by the product of the mean slice thickness in millimeters and the sum of all the cross-sectional areas minus the maximal cross-sectional area.

Measurement of volume density of the tubules and glomeruli. We used a grid drawn on transparency film containing a tessalation of "coarse" points 2 in. apart and to every "coarse" point there were 10 "fine" points. The slide of the kidney tissue was mounted onto a microscope (Nikon Inc., Garden City, NY) and the image was projected onto a screen in the center of which was placed the grid. The magnification of the system was 165 for volume density of glomeruli, and $\mathbf{6 6 0}$ for volume density of tubules. The points on the grid for tubules were 1 in apart. Always starting at the same designated corner of the slide, the slide was sequentially positioned at 0.5 -cm intervals in the horizontal and vertical axes of the slide platform. At each position the number of coarse points falling on the whole-kidney profile and tubular epithelial structures and enclosed urinary space, and the number of fine points falling on the glomerular profiles were counted. The volume densities and total volumes of the glomerular and tubular compartment were determined as follows:

(a) Volume density of the glomerular compartment $=$ (sum of fine points falling on all glomerular profiles)/(sum of coarse points falling on the whole kidney profile $\times 100$ );

(b) Total glomerular volume $=$ volume density of the glomerular compartment $\times$ total kidney volume;

(c) Volume density of the tubular compartment $=$ (sum of "coarse" points falling on all tubular epithelial profiles)/(sum of "coarse" points falling on whole kidney profile);

(d) Total tubular volume $=$ volume density of the tubular compartment $\times$ total kidney volume.

Measurement of mean glomerular volume. We measured glomerular volume as described by Hirose et al. (21). We used the same optical system to measure glomerular volume. A grid drawn on transparency film containing a tessalation of points $6.3 \mathrm{~mm}$ apart was used. The sections were systematically scanned as described and 100 glomerular profiles were counted. The grid contained "inclusion" lines at the right and upper edges which allowed the counting of the glomerular profiles that touched these lines, and the grid also contained "exclusion" lines, at the left and lower edges which excluded glomeruli that touched these lines. The mean glomerular volume (MGV) was determined as follows:

$M G V=(P \times A)^{3 / 2} \times \beta / K$,

where $P=$ average number of points per profile, $A=$ area in square micrometers represented by each point (at magnification used $A$ $=1,481), \beta=1.38$ and represents a correction factor that assumes glomeruli are spherical, $K=1.01$ and represents a correction factor that assumes the variation in glomerular volume has a coefficient of variation of $10 \%$

\section{Assessment of antioxidant status}

Measurement of glutathione peroxidase activity. The method of Lawrence and Burk (22) was employed. The kidneys were perfused with $1.14 \mathrm{M}$ sodium chloride, excised, and subsequently homogenized in $5 \mathrm{ml}$ of $0.25 \mathrm{M}$ sucrose using a polytron homogenizer at setting 8 for $15 \mathrm{~s}$. The homogenates were centrifuged for $1 \mathrm{~h}$ at $105,000 \mathrm{~g}$, and the supernatant was diluted $1: 10.0 .1 \mathrm{ml}$ of the diluted supernatant was added to $0.8 \mathrm{ml}$ of mixture consisting of $50 \mathrm{mM}$ potassium phosphate (pH 7.0), $1 \mathrm{mM}$ EDTA, $1 \mathrm{mM} \mathrm{NaN}_{3}, 0.2 \mathrm{mM}$ NADPH, one enzyme unit per milliliter of GSSG reductase, and $1 \mathrm{mM} \mathrm{GSH}$, and the reac- tion mixture was allowed to incubate for 5 min. A blank in which distilled water replaced the supernatant was also prepared with the reaction mixture. After $5 \mathrm{~min}$ of incubation, $0.1 \mathrm{ml}$ of $0.25 \mathrm{mM}$ hydrogen peroxide was added to $0.9 \mathrm{ml}$ of the incubated sample. The absorbance at $340 \mathrm{~nm}$ was followed for $5 \mathrm{~min}$ and the activity of glutathione peroxidase was calculated from the rate at which NADPH was oxidized, and expressed as nanomoles of NADPH oxidized per minute per milligram of protein. The net glutathione peroxidase activity was determined by subtracting the activity of the blank from the activity of each sample. The millimolar absorptivity for NADPH at $340 \mathrm{~nm}$ is 6.22 . All measurements in this and other assays were performed in duplicate.

Determination of lipid peroxidation by measurement of thiobarbituric acid-reactive substances (TBARS). ${ }^{1}$ We employed the method of Ohkawa et al. (23). The kidney was removed and placed in phosphatebuffered saline and subsequently homogenized with a Polytron for $15 \mathrm{~s}$ (Brinkmann Instruments Co., Westbury, NY) in $3 \mathrm{ml}$ of $100 \mathrm{mM}$ potassium chloride. To examine the effects of available iron on the extent of lipid peroxidation, homogenization was also carried out in the presence of $0.003 \mathrm{M}$ EDTA. Additionally, homogenates were also treated with $100 \mu \mathrm{M}$ iron and $400 \mu \mathrm{M}$ ascorbic acid incubated for $1 \mathrm{~h}$ as a method of inducing iron-driven lipid peroxidation. The homogenized tissue was centrifuged at $600 \mathrm{~g}$ for $10 \mathrm{~min}$. $0.4 \mathrm{ml}$ of the supernatant was added to a reaction mixture consisting of $0.2 \mathrm{ml}$ of $8.1 \%$ SDS, $1.5 \mathrm{ml}$ of $20 \%$ acetic acid, $1.5 \mathrm{ml}$ of $0.8 \%$ thiobarbituric acid, and $6.6 \mathrm{ml}$ of water. The solution was placed in a water bath at $95^{\circ} \mathrm{C}$ for 60 $\mathrm{min}$. After removal from the water bath and cooling, $1 \mathrm{ml}$ of water and $5 \mathrm{ml}$ of $n$-butanol pyridine mixture $(15: 1 \mathrm{vol} / \mathrm{vol})$ were added, the samples agitated and subsequently centrifuged at $2,000 \mathrm{~g}$ for $15 \mathrm{~min}$. The organic layer was pipetted off and the absorbance of this fraction was read at $532 \mathrm{~nm}$. Malonaldehyde tetraethylacetal was employed as the standard. The amount of TBARS was expressed per milligram protein. Protein content was determined using the Coomassie blue assay.

Measurement of kidney iron content by the bleomycin assay. Measurement of kidney iron concentration in the control and deficient animals was performed using the bleomycin assay (24), $6 \mathrm{wk}$ after dietary assignment, i.e., just before the onset of enhanced renal growth. This method does not measure iron bound to such proteins as transferrin, ferritin, hemoglobin, or myoglobin (24). The principle of this method is that bleomycin binds iron and the bleomycin-iron complex generates TBARS from DNA. The difference between the amount of TBARS generated in the presence and absence of DNA reflects the concentration of iron. In the performance of the assay all reagents except for bleomycin were made up in pyrogen-free water and treated with solid Chelex-100 resin. The kidney was homogenized in $3 \mathrm{ml}$ of Chelex-treated saline, the homogenate was centrifuged at $10,000 \mathrm{~g}$, and the resultant supernatant was used in the iron assay. The reaction mixture consisted of the following reagents in the stated order: $0.5 \mathrm{ml}$ of DNA solution, $0.05 \mathrm{ml}$ of bleomycin solution, $0.1 \mathrm{ml}$ of $50 \mathrm{mM}$ magnesium chloride, $0.05 \mathrm{ml}$ of $10 \mathrm{mM} \mathrm{HCl}, 0.1 \mathrm{ml}$ of water, $0.1 \mathrm{ml}$ of supernatant, and $0.1 \mathrm{ml}$ ascorbic acid. The DNA solution was prepared by dissolving calf thymus DNA (Sigma Chemical Co., St. Louis, MO) in water at $1 \mathrm{mg} / \mathrm{ml}$ and stored for $12 \mathrm{~h}$ at $4^{\circ} \mathrm{C}$. The solution was then stored over Chelex to remove any traces of iron. The tubes were incubated at $37^{\circ} \mathrm{C}$ for $2 \mathrm{~h}$ with continuous shaking. Each sample was assayed in the presence and absence of bleomycin and additionally, a blank without kidney supernatant was prepared with the reaction mixture. After $2 \mathrm{~h}$ the reaction was stopped by the addition of $0.1 \mathrm{ml}$ of $0.1 \mathrm{M}$ EDTA. $1 \mathrm{ml}$ of $1 \%$ thiobarbituric acid (dissolved in $0.05 \mathrm{M}$ sodium hydroxide) was added followed by $1 \mathrm{ml}$ of $25 \%$ hydrochloric acid. The reaction mixture was then incubated in a water bath at $100^{\circ} \mathrm{C}$ for $10 \mathrm{~min}$ and after cooling, the absorbance at $532 \mathrm{~nm}$ was determined. A standard curve was prepared using ferric chloride in pyrogen-free water with serial dilutions of the iron salt up to $50 \mu \mathrm{M}$.

1. Abbreviations used in this paper: EDRF, endothelial-derived relaxing factor; TBARS, thiobarbituric acid-reactive substances. 


\section{Ornithine decarboxylase assay}

Ornithine decarboxylase activity was measured by the method of Russell and Snyder (25) in freshly harvested kidneys. The kidney was homogenized in 5 vol of $50 \mathrm{mM}$ sodium hydrogen phosphate buffer (pH 7.2) and the homogenate was centrifuged at $40,000 \mathrm{~g}$ for $20 \mathrm{~min}$ $0.5 \mathrm{ml}$ of the supernatant was added to $1.5 \mathrm{ml}$ of an incubation mixture of $50 \mathrm{mM}$ sodium hydrogen potassium phosphate buffer ( $\mathrm{pH} 7.2), 0.1$ $\mathrm{mM}$ EDTA, $2 \mathrm{mM}$ dithiothreitol, $5 \mathrm{mM}$ sodium fluoride, and 0.06 $\mathrm{mM}$ pyridoxal phosphate. The incubation mixture was agitated for 10 $\min$ at $37^{\circ} \mathrm{C}$. The reaction was initiated by the addition of $1 \mu \mathrm{CL}-$ $\left[{ }^{14} \mathrm{C}\right]$ ornithine and unlabeled ornithine to a final concentration of 0.5 $\mathrm{mM}$, and the incubation allowed to continue for $30 \mathrm{~min}$ at $37^{\circ} \mathrm{C}$ Evolved ${ }^{14} \mathrm{CO}_{2}$ was trapped in a plastic well (Kontes Co., Vineland, $\mathrm{NJ}$ ), containing $2 \mathrm{M}$ sodium hydroxide, suspended above the incubation mixture. After $30 \mathrm{~min}$ of incubation $0.6 \mathrm{ml}$ of $1 \mathrm{M}$ citric acid was injected through the leak-proof rubber stopper to stop the reaction, and the incubation was allowed to continue for an additional $15 \mathrm{~min}$ to insure that all the evolved $\mathrm{CO}_{2}$ was trapped. The plastic well was then placed in $10 \mathrm{ml}$ of Omnifluor (New England Nuclear, Boston, MA) and the radioactivity was determined in a liquid scintillation spectrometer. The heated enzyme sample was run as a blank and subtracted from the experimental samples. Results were expressed as counts per minute per milligram protein.

\section{Measurement of urinary protein, IgG, albumin, and low molecular weight protein excretion}

We used the Coomassie blue assay for measurement of urine total protein excretory rates. IgG and albumin were measured by rate nephelometry using an immunochemistry analyzer (Beckman Instruments Inc., Palo Alto, CA) $(15,26)$. Goat-derived anti-rat IgG and albumin (Cappel Laboratories, Malvern, PA) were used to generate the antigen-antibody reaction used in their respective nephelometric reactions. For quantitation of low molecular weight protein excretion over $24 \mathrm{~h}$, the urine sample from each of the animals was filtered on a PM-10 membrane in an ultrafiltration cell (Amicon Corp., Danvers, MA) to permit the passage of proteins with molecular weight $<10,000$ $(15,26)$.

\section{Measurement of kidney DNA}

We employed the method of Burton (27). The kidney was homogenized in phosphate buffered saline and then washed three times with $0.2 \mathrm{~N}$ cold $\mathrm{HCLO}_{4}$. After the last washing the pellet was hydrolyzed in $0.5 \mathrm{~N} \mathrm{HClO}_{4}$ at $100^{\circ} \mathrm{C}$ for $20 \mathrm{~min}$. The sample was then centrifuged at $2,000 \mathrm{~g}$ and to $1 \mathrm{ml}$ of the supernatant were added $2 \mathrm{ml}$ of diphenylamine reagent (a $4 \%$ solution in glacial acetic acid) and $100 \mu \mathrm{l}$ of acetaldehyde $(0.16 \%$ solution in distilled water). The mixture was vortexed and then incubated at $37^{\circ} \mathrm{C}$ overnight. The samples were read at $595 \mathrm{~nm}$. A standard curve was prepared with serial dilutions of calf thymus DNA (Sigma Chemical Co.) dissolved in $0.005 \mathrm{M}$ potassium hydroxide.

\section{Measurement of plasma chemistries and muscle potassium content}

Potassium was measured on a flame photometer (model SLM3 flame photometer, Radiometer Co., Copenhagen) and muscle potassium content was determined as milliequivalents of potassium $/ 100 \mathrm{~g}$ dry weight in a sample of rectus abdominus muscle that was dissolved in concentration nitric acid. Blood glucose was performed in the morning in nonfasted rats by a glucometer (Ames Division, Miles Laboratories, Elkhart, IN) and plasma bicarbonate levels were determined by a Synchron AS/Astra Analyzer (Beckman Astra, Brea, CA) that measured total plasma $\left[\mathrm{CO}_{2}\right]$.

\section{Measurement of urinary ammonia excretion}

Total ammonia $\left(\mathrm{NH}_{3}+\mathrm{NH}_{4}^{+}\right)$urinary excretory rates were measured using the Sigma Diagnostics ammonia kit (Sigma Diagnostics, St. Louis, MO). This method measures the decrease in absorbance at 340 $\mathrm{nm}$ as NADH is oxidized in the reductive animation of 2-oxoglutarate in the presence of glutamate dehydrogenase (3). The rate at which NADH is oxidized is dependent on the ammonia concentration (3).

\section{Measurement of plasma ammonia concentration and renal production of ammonia}

In additional groups of rats, we measured total arterial plasma ammonia concentration and renal production of ammonia 6-7 wk after dietary assignment. We used the above enzymic assay for the determination of ammonia concentration in arterial and renal venous plasma. Renal production of ammonia was determined in vivo under euvolemic conditions as described by Tolins et al. (3), and was calculated as the product of renal blood flow and the renal venous-arterial plasma difference in ammonia concentration plus the urinary excretion of ammonia.

\section{Measurement of plasma amino nitrogen concentration}

We used the method of Goodwin (28). To $250 \mu$ l of plasma, $250 \mu$ l of $\mathrm{dH}_{2} \mathrm{O}$ was added, followed by $2 \mathrm{ml} 1.3 \%$ sodium tungstate (in $0.11 \mathrm{~N}$ $\mathrm{HCl})$ to precipitate plasma proteins. The solution was filtered and centrifuged and $1 \mathrm{ml}$ of the supernatant was incubated at $70^{\circ}$ for 15 min with $1 \mathrm{ml}$ of a solution of 1-fluro-2-4-dinitrobenzene dissolved in acetone and diluted 1:10 with a 5\% sodium tetraborate solution. The samples were allowed to cool and $2.5 \mathrm{ml}$ of acidified 1:4 dioxane was added. Absorbance was determined at $420 \mathrm{~nm}$. Standards were prepared with glutamic acid and glycine.

\section{Effect of chronic bicarbonate supplementation on renal growth}

To chronically suppress renal ammoniagenesis, we studied additional groups of animals supplemented with potassium bicarbonate $\left(\mathrm{KHCO}_{3}\right)$ given in the drinking water. We used $\mathrm{KHCO}_{3}$ since both $\mathrm{K}^{+}$ and $\mathrm{HCO}_{3}^{-}$independently suppress renal ammoniagenesis (29). Weanling rats were maintained on the control diet and received tap water or tap water containing $100 \mathrm{~m} \mathrm{M} \mathrm{KHCO}_{3}$ ad libitum for 12 wk. Similarly, weanling rats were placed on the deficient diet and received tap water or tap water containing $100 \mathrm{~m} \mathrm{M} \mathrm{KHCO}$ ad libitum for $12 \mathrm{wk}$.

\section{Effect of dietary deficiency of antioxidants on the hypertrophic response to unilateral nephrectomy}

Weanling male rats were assigned to the control and deficient diets as described. After 2 wk the right kidney was removed and the animals maintained for an additional $7 \mathrm{wk}$. At this time point urinary protein excretory rates were measured and the remaining kidney was harvested.

\section{Statistics}

All results are expressed as means \pm standard error for the means. The unpaired Student $t$ test was employed for statistical comparisons between the groups and results were considered significant for $P<0.05$.

\section{Results}

\section{Descriptive studies}

Somatic growth, food intake, and urine volumes. After dietary assignment at $3 \mathrm{wk}$ of age, diets were maintained for an additional $14 \mathrm{wk}$. At this time point two animals from an initial cohort of nine animals on the deficient diet died whereas no deaths occurred in the animals on the control diet. A characteristic feature of dietary deficiency of vitamin $\mathrm{E}$ and selenium is a slower rate of somatic growth which emerges some 7-8 wk after the imposition of the diet: by $13 \mathrm{wk}$ the deficient animals were almost $90 \mathrm{~g}$ lighter than the control animals (Table II). There were no significant differences in food intake between the two groups for the duration of the study, although the animals on the deficient diets tended to consume less food. 
Table II. Sequential Body Weights, Food Intakes, and Urine Volumes at 1, 3, 5, 7, 9, 11, 13, wk after Assignment of Weanling Rats to Control or Deficient Diets

\begin{tabular}{|c|c|c|c|c|c|c|}
\hline \multirow[b]{2}{*}{ Week } & \multicolumn{2}{|c|}{ Body weight } & \multicolumn{2}{|c|}{ Food intake } & \multicolumn{2}{|c|}{ Urine volume } \\
\hline & Control & Deficient & Control & Deficient & Control & Deficient \\
\hline & \multicolumn{4}{|c|}{$g$} & \multicolumn{2}{|c|}{$m l$} \\
\hline 1 & $85 \pm 3$ & $84 \pm 1$ & - & - & - & - \\
\hline 3 & $148 \pm 2$ & $148 \pm 2$ & $18 \pm 1$ & $16 \pm 1$ & $9 \pm 1$ & $11 \pm 1$ \\
\hline 5 & $239 \pm 3$ & $226 \pm 4$ & $22 \pm 1$ & $20 \pm 1$ & $11 \pm 1$ & $11 \pm 1$ \\
\hline 7 & $295 \pm 8$ & $285 \pm 8$ & $20 \pm 1$ & $18 \pm 1$ & $7 \pm 1$ & $14 \pm 1^{*}$ \\
\hline 9 & $333 \pm 8$ & $304 \pm 7^{*}$ & $21 \pm 1$ & $20 \pm 1$ & $8 \pm 2$ & $15 \pm 1^{*}$ \\
\hline 11 & $362 \pm 8$ & $309 \pm 7^{*}$ & $24 \pm 1$ & $22 \pm 1$ & $12 \pm 1$ & $21 \pm 2^{*}$ \\
\hline 13 & $400 \pm 8$ & $316 \pm 7^{*}$ & $22 \pm 1$ & $21 \pm 1$ & $13 \pm 2$ & $24 \pm 3^{*}$ \\
\hline
\end{tabular}

Data for weeks 1-9 are from a cohort of animals maintained for 9 wk after dietary assignment (control $=6$ and deficient $=9$ ) and data for weeks 9-14 are from a cohort of animals maintained for $14 \mathrm{wk}$ after dietary assignment (control $=7$ and deficient $=9$ ).

${ }^{*} P<0.05$ or less.

Decreased somatic growth for a given amount of food intake is a well-recognized feature of selenium deficiency (9). Urine volumes were similar between the two groups for up to $6 \mathrm{wk}$ after dietary assignment. Thereafter, urine output was increased almost two-fold in the deficient animals. Throughout the $14 \mathrm{wk}$ of observation, the deficient animals displayed no unusual characteristics; in particular, the skin and hair appeared healthy without the features of essential fatty acid deficiency such as scaling of the skin and tail, and loss of body hair. Additionally, the animals were active and exhibited no musculoskeletal abnormalities or weakness.

Kidney and other organ weights. By 9 wk after dietary assignment a significant and persistent increase in kidney wet weight occurred in the animals on the deficient diet (Table III). Mean kidney weights in the deficient animals, $1.36 \pm 0.07 \mathrm{~g}$, were significantly higher than in the control animals, $1.03 \pm 0.03 \mathrm{~g}$ representing an increase of $\sim 30 \%$. This enhancement of renal growth persisted for the remaining $5 \mathrm{wk}$ of observation in spite of the opposing trend of lesser somatic growth in the deficient animals. Normalized for body weight, the wet weight of the kidney per $100 \mathrm{~g}$ of body weight was increased at 9,11 , and 14 wk by well over $50 \%$ in deficient rats (Fig. 1). The increment in visceral weight in the deficient animals appeared uniquely directed to the kidney since other organs such as the liver, were either not significantly different in weight $(10.84 \pm 0.40$ vs. $11.52 \pm 0.24 \mathrm{~g})$ or in fact, lower in

Table III. Wet Kidney Weights in Control and Deficient Animals at 6, 9, 11, and 14 wk after Dietary Assignment

\begin{tabular}{rccc}
\hline & Control & Deficient & $P$ value \\
\hline & & & \\
$6 \mathrm{wk}$ & $0.97 \pm 0.02(n=5)$ & $1.05 \pm 0.05(n=7)$ & $\mathrm{NS}$ \\
$9 \mathrm{wk}$ & $1.03 \pm 0.03(n=6)$ & $1.36 \pm 0.07(n=9)$ & $<0.01$ \\
$11 \mathrm{wk}$ & $1.15 \pm 0.05(n=7)$ & $1.47 \pm 0.04(n=5)$ & $<0.01$ \\
$14 \mathrm{wk}$ & $1.30 \pm 0.04(n=7)$ & $1.45 \pm 0.04(n=7)$ & $<0.05$ \\
& & &
\end{tabular}

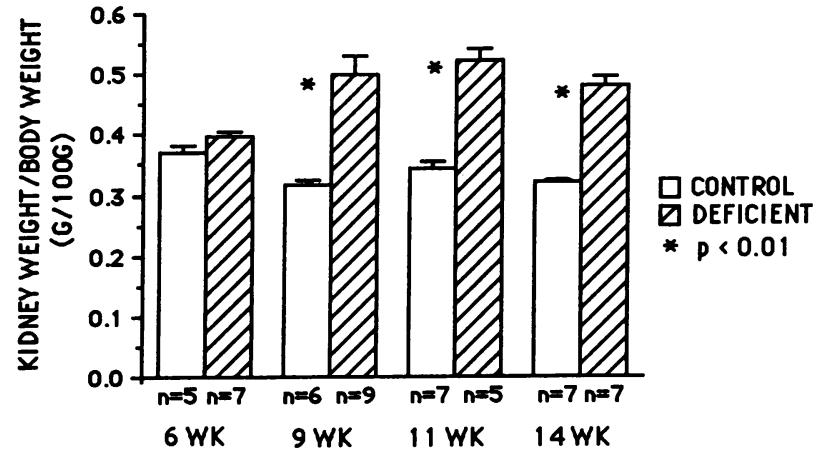

Figure 1. Sequential kidney weight/body weight ratios in rats maintained on control and deficient diets 6, 9, 11, and $14 \mathrm{wk}$ after dietary assignment.

weight such as the heart $(0.91 \pm 0.02$ vs. $1.05 \pm 0.02 \mathrm{~g}, P<0.01)$. The increment in wet weight of the kidney at $9 \mathrm{wk}$ was accompanied by increases in dry weight $(0.32 \pm 0.01$ vs. $0.27 \pm 0.01 \mathrm{~g}$, $P<0.01)$ and in protein content $(150.1 \pm 5.1$ vs. $128.2 \pm 1.4 \mathrm{mg}$, $P<0.01)$. DNA per kidney was also increased in the deficient animals as compared to the control animals $(4.67 \pm 0.24 \mathrm{vs}$. $3.58 \pm 0.07 \mathrm{mg}, P<0.01$ ). Thus, in addition to increased wet weight of the kidney there were increments in dry weight, protein, and DNA contents in the kidney of the animals maintained on the deficient diet.

Morphometric and histologic studies. To determine whether increased kidney weight was accompanied by renal enlargement, morphometric studies were undertaken at 9 and 14 wk after dietary assignment. Kidney volume in the deficient animals was significantly increased as compared to the values observed in the control animals at both 9 and 14 wk after dietary assignment, representing some $30 \%$ increase in kidney volume (Fig. 2, left panel). Measurement of volume density of the tubular epithelium showed no differences in the control and deficient animals when studied at 9 wk $(80.1 \pm 0.4$ vs. $78.7 \pm 1.4 \%, P=\mathrm{NS})$ and at $14 \mathrm{wk}(78.5 \pm 1.5$ vs. $77.2 \pm 1.4 \%, P$ = NS) after dietary assignment. However, the total volume occupied by the tubular epithelium and enclosed urinary space was significantly increased in the deficient as compared to the control animals at both time points (Fig. 2, right panel). Thus, increased kidney weight is accompanied by increments in kidney volume and in total tubular epithelial volume, thus representing structural hypertrophy of the nephron in the animals subjected to the deficient diets.

The volume densities of the glomerular compartment in the control and deficient animals were not significantly different either at $9 \mathrm{wk}(3.5 \pm 0.2$ vs. $2.9 \pm 0.3 \%, P=\mathrm{NS})$ or at $14 \mathrm{wk}$ $(3.3 \pm 0.1$ vs. $3.1 \pm 0.1 \%, P=N S)$ after dietary assignment. At 9 wk there was a tendency for increased total glomerular volume in the deficient animals (Fig. 3, left panel). These differences were significant at $14 \mathrm{wk}$ (Fig. 3, left panel). Additionally, mean glomerular volume in the deficient animals at $14 \mathrm{wk}$ was significantly increased as compared to the control animals at this time, $\left(1.24 \pm 0.05\right.$ vs. $\left.1.09 \pm 0.02 \times 10^{6} \mu \mathrm{m}^{3}, P<0.05\right)$ (Fig. 3 , right panel). Thus, renal growth owing to dietary deficiency of antioxidants involves enlargement of the glomerulus and the tubular epithelium.

Qualitative histologic examination failed to reveal any glomerular abnormalities at the light microscopic level. Nor were there any discernible differences in the tubular epithelium be- 

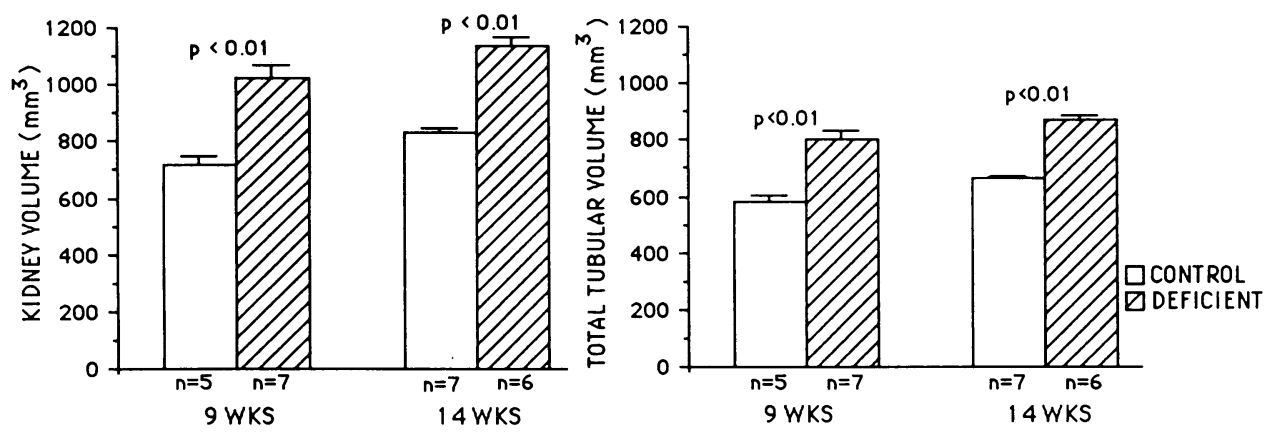

Figure 2. Kidney volume (left panel) and total tubular epithelial volume (right panel) in cubic millimeters in rats maintained on control and deficient diets 9 and $14 \mathrm{wk}$ after dietary assignment.

tween the control and deficient animals. A prominent aspect of the interstitium of the deficient animals observed at $9 \mathrm{wk}$ and more marked at $14 \mathrm{wk}$ was scattered foci of cellular infiltrate which encroached upon some tubules (Fig. 4).

Determination of nephron number. Determination of nephron number by the colloidal carbon technique revealed no significant differences in such counts in animals maintained on the control and deficient diets, $25,425 \pm 964$ vs. $26,745 \pm 754$. Nephron number was also calculated from the morphometric data derived in animals studied $14 \mathrm{wk}$ after dietary assignment. In these studies nephron number was not significantly different in animals on the control and deficient diets, $25,953 \pm 1,579$ vs. $28,147 \pm 1,306$. Thus, the differences in the size of the kidney could not be ascribed to differences in population of nephrons since determination of nephron number by two different techniques revealed comparable number of nephrons in each dietary group.

Urinary protein excretory rates per $24 h$. Rates of protein excretion in the animals maintained for $9 \mathrm{wk}$ are shown in Fig. 5 (left panel). Increased rates of protein excretion were noted 8 wk after dietary assignment and persisted for the additional week of observation. These augmented rates of total protein excretion were also accompanied by increased urinary excretion of albumin $(5.87 \pm 1.47$ vs. $1.96 \pm 0.34 \mathrm{mg} / 24 \mathrm{~h}, P=0.054)$ and increased excretion of low molecular weight proteins, i.e., $<10,000 \mathrm{~mol} \mathrm{wt}(0.23 \pm 0.03$ vs. $0.13 \pm 0.01 \mathrm{mg} / 24 \mathrm{~h}, P$ $<0.02$ ). We also measured urinary excretion of IgG in an additional cohort of deficient $(n=6)$ and control $(n=5)$ rats 9 wk after dietary assignment. In four control animals, urinary IgG concentration was below the lower assay limits of our nephelometric method to be detected while in the remaining rat the excretory rate was $105 \mu \mathrm{g} / 24 \mathrm{~h}$. The mean rate of $\mathrm{IgG}$ excretion in the deficient animals was $254.1 \pm 23.1 \mu \mathrm{g} / 24 \mathrm{~h}$ with a range of $169.1-302.5 \mu \mathrm{g} / 24 \mathrm{~h}$. Thus, at 9 wk the deficient animals displayed increased urinary excretory rates for total protein, IgG, albumin, and low molecular weight proteins.

Such increased rates of urinary total protein excretion appearing at $8 \mathrm{wk}$ after dietary assignment persisted for the duration of the study as demonstrated by the cohort of animals maintained for $14 \mathrm{wk}$ (Fig. 5, right panel). By the 14th week of observation there was almost a two-fold increment in absolute rates of protein excretion in the deficient animals as compared to the control animals. Thus, increased rates of protein excretion accompany increased kidney size observed in the animals deficient in dietary sources of antioxidants.

Renal hemodynamic studies. Renal hemodynamic measurements were undertaken after renal growth and injury were established in the deficient animals. The results of the hemodynamic measurements undertaken at $11 \mathrm{wk}$ are shown in Table IV. The deficient animals demonstrated increased mean arterial pressure during these clearance studies as compared to the control animals $(131 \pm 3$ vs. $117 \pm 5 \mathrm{mmHg}, P<0.05)$. Accompanying this elevation in systemic arterial pressure were diminished glomerular filtration and renal plasma flow rates. Similarly, renal blood flow rates were diminished to approxi-

\section{MORPHOMETRIC ANALYSIS}

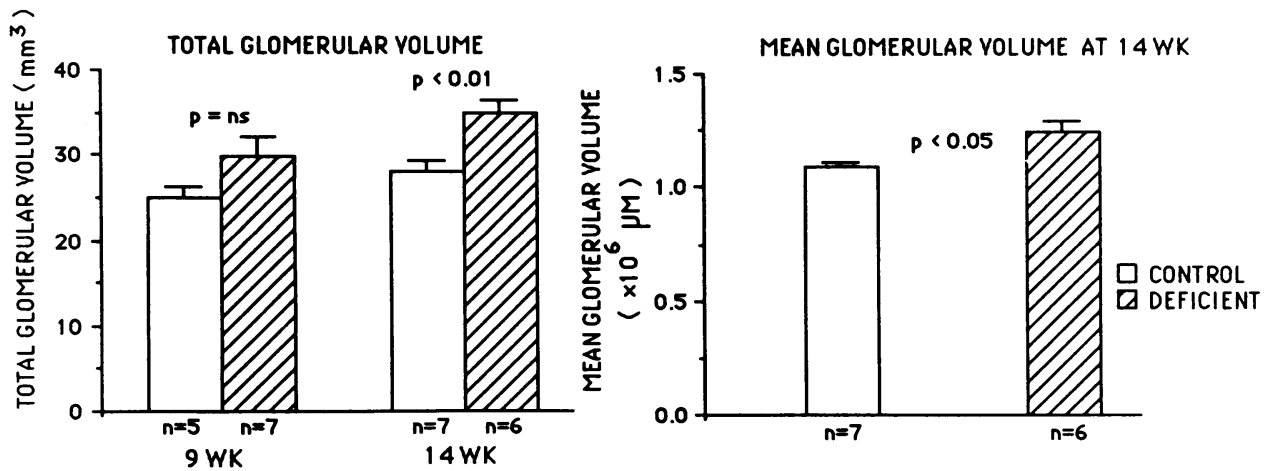

Figure 3. Total glomerular volume in rats maintained on control and deficient diets 9 and $14 \mathrm{wk}$ after dietary assignment (left panel) and mean glomerular volumes in control and deficient rats determined at 14 weeks (right panel). 

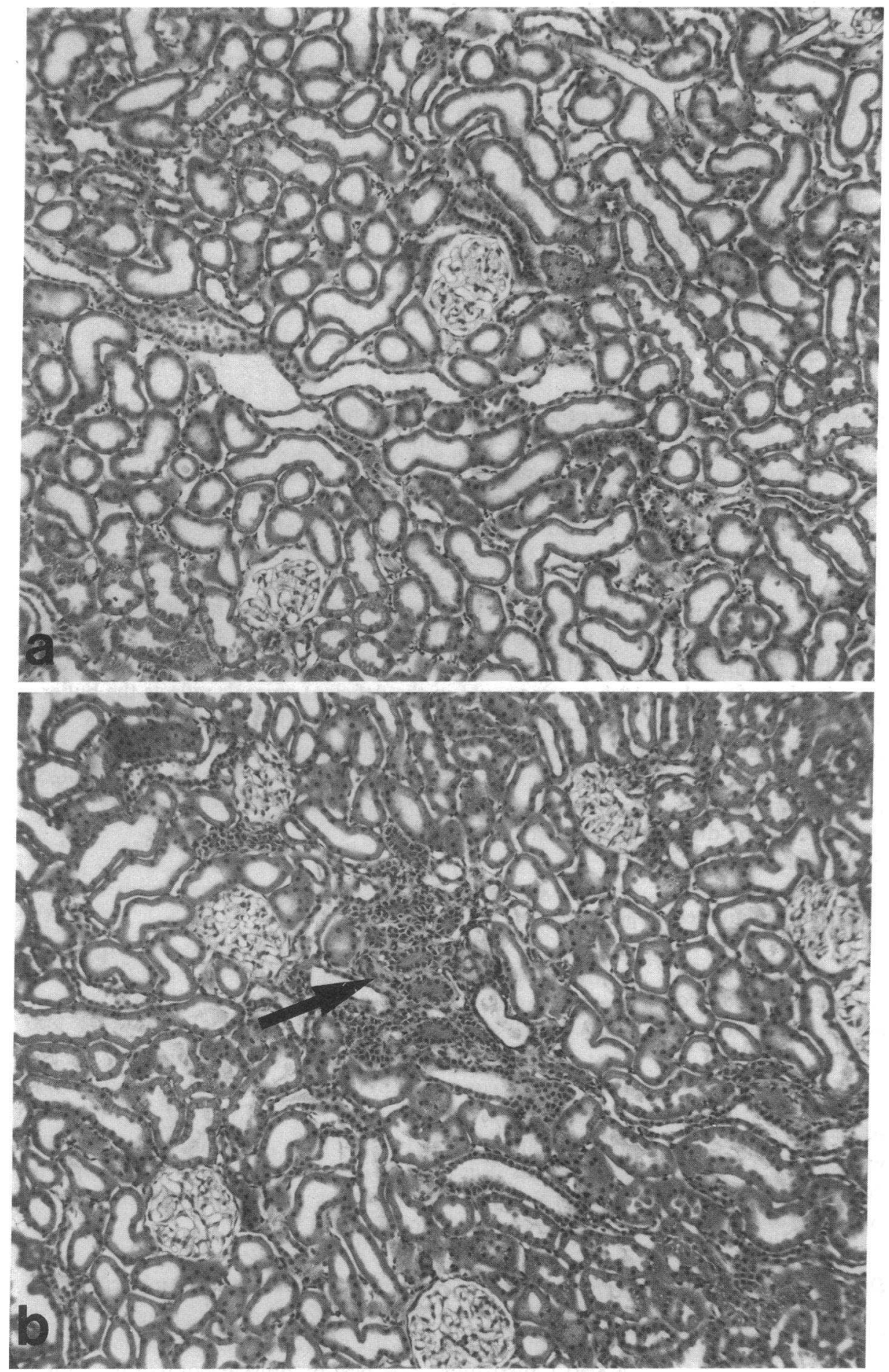

Figure 4. Sections of kidney cortex in rats maintained on $(a)$ control and $(b)$ deficient diets examined by light microscopy at $\times 120,9 \mathrm{wk}$ after dietary assignment. The kidneys from rats on the deficient diet display focal interstitial cellular infiltration (arrow).

mately half the value in the control animals. Mean renal vascular resistance in the deficient animals was significantly increased as compared to the control animals. Thus, at a relatively late stage in this model when renal hypertrophy is established and is accompanied by increased rates of protein excretion, there is impairment of glomerular filtration and plasma flow rates and increased vascular resistances.

Renal hemodynamic and micropuncture studies. To determine whether alterations in glomerular hemodynamics antedated the appearance of growth and injury in the deficient animals such hemodynamic measurements were undertaken 6 wk after dietary assignment, i.e., just before the appearance of these changes. These data are shown in Table V. As demonstrated, there were no significant differences in either wholekidney or single nephron filtration and plasma flow rates. Similarly, no differences in glomerular pressures were detectable. The calculated glomerular ultrafiltration coefficient were similar in the two groups. Thus, renal and glomerular hemodynamic measurements were similar in the deficient and control animals and, thus, it is unlikely that alterations in glomerular 


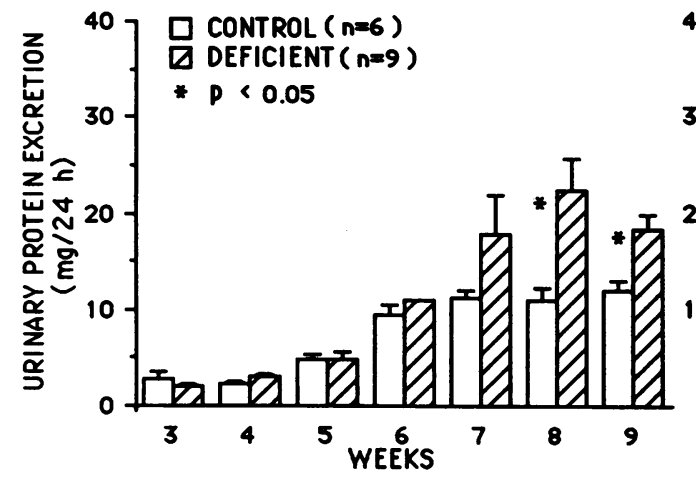

hemodynamics were instrumental or permissive in the enhancement of renal growth and injury that ultimately ensued in this model. It should be pointed out that at this stage, that is, before the appearance of enhanced renal growth, no significant differences in systemic arterial pressure were apparent, although at a later stage when growth and injury were present, the deficient animals were mildly hypertensive.

Effect of the dietary manipulation on remnant kidney hypertrophy. In addition to the effects on growth of the intact kidney, we also examined the effects of this dietary manipulation on the hypertrophic response following reduction of renal mass. Reduction of renal mass increased the differences in wet kidney weight between the control and deficient animals. The absolute weight of the remaining kidney in the deficient animals, was increased by $\sim 50 \%$ as compared to the remaining kidney in the animals maintained on the control diet $(2.02 \pm 0.19$ vs. $1.36 \pm 0.03 \mathrm{~g}, P<0.05)$. These differences were even more pronounced when expressed per $100 \mathrm{~g}$ of body weight $(0.878 \pm 0.089$ vs. $0.432 \pm 0.009, P<0.01)$. The uninephrectomized animals on the deficient diet also displayed higher rates of protein excretion $(16.9 \pm 1.8$ vs. $9.8 \pm 0.4 \mathrm{mg} / 24$ $\mathrm{h}, P<0.05)$. Thus, in response to uninephrectomy, enhanced growth of the remaining kidney is exhibited in animals maintained on the deficient diet.

\section{Mechanistic studies}

MEASUREMENT OF AMMONIA EXCRETION

We examined whether induction of growth and injury by dietary deficiency of antioxidants was due to increased ammoniagenesis. This premise is based on the observations of Gol-

Table IV. Clearance Data in Control and Deficient Animals 11 wk after Dietary Assignment

\begin{tabular}{lccc}
\hline & $\begin{array}{c}\text { Control } \\
(n=7)\end{array}$ & $\begin{array}{c}\text { Deficient } \\
(n=5)\end{array}$ & $P$ value \\
\hline $\begin{array}{l}\text { Mean arterial pressure } \\
(\mathrm{mmHg})\end{array}$ & $117 \pm 5$ & $131 \pm 3$ & $<0.05$ \\
$\begin{array}{c}\text { Glomerular filtration } \\
\text { rate }(\mathrm{ml} / \mathrm{min})\end{array}$ & $1.22 \pm 0.11$ & $0.72 \pm 0.17$ & $<0.01$ \\
$\begin{array}{c}\text { Renal plasma flow rate } \\
(\mathrm{ml} / \mathrm{min})\end{array}$ & $4.99 \pm 0.62$ & $2.82 \pm 0.71$ & $<0.05$ \\
$\begin{array}{c}\text { Renal blood flow rate } \\
(\mathrm{ml} / \mathrm{min})\end{array}$ & $9.52 \pm 1.13$ & $5.24 \pm 1.32$ & $<0.05$ \\
$\begin{array}{c}\text { Renal vascular resistance } \\
(\mathrm{mmHg} \cdot \mathrm{min} / \mathrm{ml})\end{array}$ & $12.9 \pm 1.0$ & $34.8 \pm 10.2$ & $<0.05$ \\
\hline
\end{tabular}

chini et al. (30) that ammonia is a stimulus to renal hypertrophy and our observations that ammonia exerts pro-inflammatory effects in the kidney (26). We measured sequential urinary excretory rates for ammonia before the onset of growth and injury, i.e., at 4, 5, and 6 wk after dietary assignment. These data are summarized in Fig. 6. Rats on the deficient diet excreted increased amounts of ammonia. Urinary $\mathrm{pH}$ in urine collected during the $24-\mathrm{h}$ metabolic collection was higher in the deficient animals as compared to the control animals, $7.32 \pm 0.23$ vs. $6.64 \pm 0.06, P<0.05$. The higher urinary $\mathrm{pH}$ in the deficient animals reflects the buffering capacity of the additional ammonia generated by the kidney of the deficient rats. Sequential measurements of urinary ammonia excretory rates failed to reveal significant differences between the two groups in the first, second, and third weeks after dietary assignment.

\section{PLASMA AMMONIA CONCENTRATION AND RENAL} PRODUCTION OF AMMONIA

Arterial plasma ammonia concentrations were not significantly different in the control and deficient animals (Fig. 7, left panel). Thus the increased urinary excretion of ammonia cannot be ascribed to increased circulating levels of ammonia. That renal ammoniagenesis was increased in rats on the deficient diet was confirmed by our measurements of renal ammonia production, determined at $1.65 \pm 0.22 \mu \mathrm{mol} / \mathrm{min}$ in the deficient animals compared to $0.92 \pm 0.20 \mu \mathrm{mol} / \mathrm{min}$ in the control animals (Fig. 7, right panel). Thus dietary deficiency of vitamin $E$ and selenium induces increased renal production of ammonia measured in vivo.

MUSCLE POTASSIUM CONTENT AND SERUM CHEMISTRIES In control $(n=5)$ and deficient $(n=6)$ rats there were no significant differences in serum potassium $(4.8 \pm 0.1 \mathrm{vs}$. $4.8 \pm 0.1 \mathrm{meq} / \mathrm{liter}, P=\mathrm{NS}$ ) or muscle potassium content $(35.9 \pm 0.8$ vs. $34.4 \pm 0.9 \mathrm{meq} / 100 \mathrm{~g}$ of dry weight). Thus, the structural changes observed in the kidneys of the deficient animals as well as the augmented rates of ammonia excretion were not due to potassium depletion. Serum bicarbonate and glucose were measured in an additional cohort of control and deficient animals ( $n=5$ in each group). No significant differences were observed for serum bicarbonate $(25.8 \pm 0.4 \mathrm{vs}$. $26.4 \pm 0.5 \mathrm{meq} / \mathrm{liter})$ or serum glucose $(114 \pm 8 \mathrm{vs}$. $119 \pm 4$ $\mathrm{mg} / \mathrm{dl})$. Thus, the induction of growth and injury in kidneys of rats maintained on the deficient diets could not be ascribed to hypokalemic nephropathy, metabolic acidosis, or diabetic-induced renal growth. 
Table V. Glomerular Hemodynamic Measurements in Control and Deficient Animals 6 wk after Dietary Assignment

\begin{tabular}{|c|c|c|c|}
\hline & $\begin{array}{l}\text { Control } \\
(n=5)\end{array}$ & $\begin{array}{l}\text { Deficient } \\
(n=7)\end{array}$ & $P$ value \\
\hline Body weight (g) & $262 \pm 6$ & $264 \pm 8$ & NS \\
\hline Hematocrit (\%) & $46 \pm 1$ & $47 \pm 1$ & NS \\
\hline $\begin{array}{l}\text { Mean arterial press } \\
\quad(m m H g)\end{array}$ & $131 \pm 4$ & $135 \pm 2$ & NS \\
\hline $\begin{array}{l}\text { Glomerular filtratic } \\
\text { rate }(\mathrm{ml} / \mathrm{min})\end{array}$ & $1.03 \pm 0.04$ & $1.03 \pm 0.03$ & NS \\
\hline $\begin{array}{l}\text { Renal plasma flow } \\
(\mathrm{ml} / \mathrm{min})\end{array}$ & $4.18 \pm 0.64$ & $4.52 \pm 0.20$ & NS \\
\hline Filtration fraction & $0.26 \pm 0.02$ & $0.23 \pm 0.01$ & NS \\
\hline $\begin{array}{l}\text { Single nephron } \\
\text { glomerular filtrat } \\
\text { rate }(\mathrm{nl} / \mathrm{min})\end{array}$ & $38 \pm 3$ & $32 \pm 2$ & NS \\
\hline$P_{\mathrm{GC}}(m m H g)$ & $69 \pm 3$ & $68 \pm 3$ & NS \\
\hline$\Delta P(m m H g)$ & $56 \pm 1$ & $54 \pm 3$ & NS \\
\hline$Q_{\mathrm{A}}(\mathrm{nl} / \mathrm{min})$ & $157 \pm 30$ & $144 \pm 13$ & NS \\
\hline$C_{\mathrm{A}}(\mathrm{g} / 100 \mathrm{ml})$ & $5.9 \pm 0.1$ & $5.9 \pm 0.1$ & NS \\
\hline$K_{\mathrm{f}}(n l / s \cdot m m H g)$ & $0.021 \pm 0.001$ & $0.019 \pm 0.002$ & NS \\
\hline
\end{tabular}

Nomenclature: $P_{\mathrm{GC}}$, glomerular capillary hydraulic pressure; $\Delta P$, transcapillary hydraulic pressure gradient; $Q_{\mathrm{A}}$, glomerular capillary plasma flow rate; $C_{\mathrm{A}}$, afferent arteriolar protein concentration; $K_{\mathrm{f}}$, glomerular ultrafiltration coefficient.

PLASMA AMINO NITROGEN CONCENTRATION

We investigated whether increased renal ammoniagenesis was due to increased delivery of amino acids to the kidney by measuring plasma amino nitrogen in control and deficient rats. As shown in Fig. 8 circulating levels of amino acids were almost identical in the two dietary groups. Thus increased renal production of ammonia was not due to increased amino acid delivery.

EFFECT OF CHRONIC BICARBONATE SUPPLEMENTATION ON RENAL GROWTH

$\mathrm{KHCO}_{3}$ supplementation effectively suppressed renal ammonia production measured as urinary ammonia excretion in rats maintained on the control diet. In rats maintained on the control diet and supplemented with $100 \mathrm{mM} \mathrm{KHCO}_{3}$ in the drinking water $(n=8)$, urinary ammonia excretion at $6 \mathrm{wk}$ measured at $0.08 \pm 0.01 \mathrm{mmol} / 24 \mathrm{~h}$ was strikingly lower that the urinary ammonia excretory rates displayed in rats receiving tap water without $\mathrm{KHCO}_{3}, 0.23 \pm 0.03 \mathrm{mmol} / 24 \mathrm{~h}(n=6)$. $\mathrm{KHCO}_{3}$ supplementation led to significantly reduced wet kidney weights. $(1.12 \pm 0.04$ vs. $1.29 \pm 0.04 \mathrm{~g}, P<0.02)$ without affecting body weights ( $345 \pm 11$ vs. $351 \pm 5 \mathrm{~g}, P=\mathrm{ns})$ or mean arterial pressure $(115 \pm 2$ vs. $121 \pm 4 \mathrm{mmHg}, P=\mathrm{ns})$ in these animals when sacrificed at $12 \mathrm{wk}$. Thus chronic suppression of renal ammoniagenesis in rats with intact kidneys and maintained on the control diets leads to blunted kidney growth.

$\mathrm{KHCO}_{3}$ failed to significantly reduce urinary ammonia excretion measured at $6 \mathrm{wk}$ in rats maintained on the deficient diets; rats supplemented with $\mathrm{KHCO}_{3}(n=9)$ exhibited urinary ammonia excretory rates of $0.45 \pm 0.11 \mathrm{mmol} / 24 \mathrm{~h}$ that were not significantly different from excretory rates in rats not supplemented with $\mathrm{KHCO}_{3}, 0.60 \pm 0.17 \mathrm{mmol} / 24 \mathrm{~h}(n=6)$. $\mathrm{KHCO}_{3}$ supplementation failed to significantly alter body weights $(270 \pm 9$ vs. $280 \pm 10 \mathrm{~g}, P=\mathrm{NS})$ or kidney weights $(1.47 \pm 0.04$ vs. $1.40 \pm 0.04 \mathrm{~g}, P=\mathrm{NS})$ in animals on the deficient diets killed at $12 \mathrm{wk}$. Thus the enhanced ammonia production and enhanced renal growth induced by the deficient diet are resistant to chronic $\mathrm{KHCO}_{3}$ supplementation.

\section{ASSESSMENT OF THE ANTIOXIDANT STATUS}

Measurement of glutathione peroxidase. To demonstrate the efficacy of our dietary manipulation, we measured the activity of glutathione peroxidase in the kidney in animals subjected to the deficient and control diets. The deficient diets markedly attenuated glutathione peroxidase activity to $<5 \%$ of the control value $(7.8 \pm 1.8 \mathrm{vs}$. $186.9 \pm 8.7 \mathrm{nmol} / \mathrm{min}$ per $\mathrm{mg}$ protein, $P$ $<0.001, n=3$ in each group) thereby confirming that the dietary regimen achieved effective selenium deficiency.

Determination of lipid peroxidation. We determined the extent of lipid peroxidation by measuring the amount of TBARS under three conditions. In the presence of the iron chelator EDTA we were unable to detect differences in TBARS in the kidneys of rats maintained on the control and deficient diets (Fig. 9, left panel). However, the deficient diet provoked marked increments in renal concentration of TBARS in the absence of EDTA (Fig. 9, middle panel) and in the presence of exogenously added iron and ascorbic acid without added EDTA (Fig. 9, right panel). These data thus confirm the marked deficiency in the antioxidant scavenging ability of these diets and their particular susceptibility to the lipid-peroxidizing effects of iron.

Measurement of kidney iron. In view of the pronounced effect of iron to promote lipid peroxidation in the kidney of animals maintained on deficient diets, we questioned whether iron concentration was increased in the kidney of animals deficient in vitamin $\mathrm{E}$ and selenium, thereby providing a pathway for the renal effects we observed. We used the bleomycin assay since it provides a method for detecting iron as well as providing another assay system for assessing impairment of antioxidant scavenging ability of renal tissue from deficient animals (24). The differences between the amount of TBARS generated in the presence and absence of bleomycin is a measure of the free iron content (Fig. 10). The differences between TBARS in the presence and absence of bleomycin were similar in the control and deficient kidneys $\left(\Delta \mathrm{OD}_{532}\right.$ were $1.71 \pm 0.07$ and $1.65 \pm 0.07 \mathrm{U}$, respectively, $P=\mathrm{NS}$ ) and, thus, the iron concentrations in the kidney, were not significantly

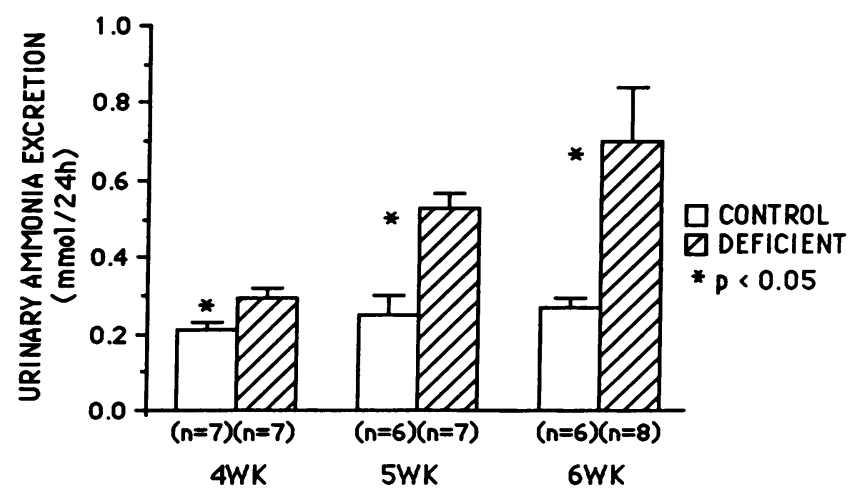

Figure 6. Urinary total ammonia $\left(\mathrm{NH}_{3}+\mathrm{NH}_{4}^{+}\right)$excretory rates in rats maintained on the control and the deficient diets at 4, 5, and 6 wk after dietary assignment. 

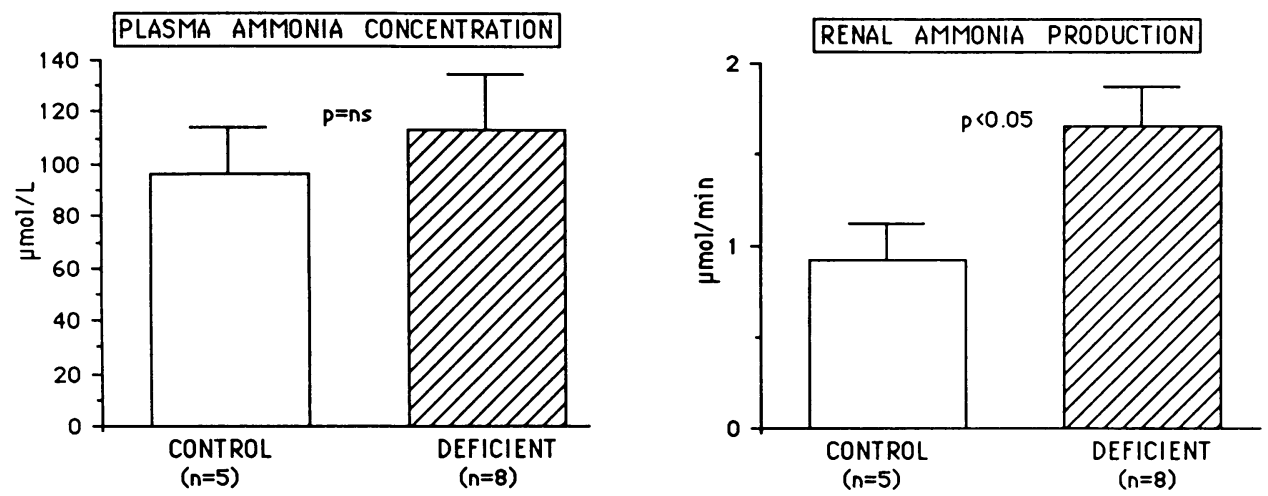

Figure 7. Arterial plasma ammonia concentration (left panel) and renal production of ammonia (right panel) in rats maintained on the control and deficient diets for 6-7 wk.

different in the control and deficient animals $(32.5 \pm 0.7$ vs. $31.4 \pm 1.3 \mu \mathrm{mol} /$ liter) (Fig. 10). Interestingly, however, the absolute quantities of TBARS in the deficient animals were strikingly higher than the values displayed by the control animals, both in the presence and in the absence of bleomycin, again reflecting the deficiency in the antioxidant status of animals maintained on vitamin $\mathrm{E}$ and selenium.

\section{ORNITHINE DECARBOXYLASE ASSAY}

To determine whether induction of ornithine decarboxylase activity accounted for the enhanced renal growth we observed, ornithine decarboxylase activity was measured in the kidneys in three rats maintained on the control or the deficient diets for $6 \mathrm{wk}$. Ornithine decarboxylase activity in the deficient animals was not increased as compared to enzymic activity in the control animals $\left(23.7 \pm 4.9\right.$ vs. $61.5 \pm 14.4 \times 10^{2} \mathrm{cpm} / \mathrm{mg}$ protein, $P$ $=$ NS). Thus, the mechanism underlying enhanced renal growth in animals maintained on the deficient diets was not due to the induction of ornithine decarboxylase.

\section{Discussion}

Our data demonstrate that dietary deficiency of antioxidants, vitamin $E$ and selenium, stimulates renal growth while inhibiting overall somatic growth. That the increase in renal size represented a hypertrophic and hyperplastic response and was not simply a consequence of increased water content is indicated by increased dry weight, protein content, and DNA content of the kidney in animals maintained on the deficient diets. In addition to these biochemical markers of renal growth, we also provide morphometric data attesting to structural enlargement. Morphometric analyses undertaken at two time points in the course of dietary restriction demonstrated increased kidney volume and increased total tubular epithelial volume

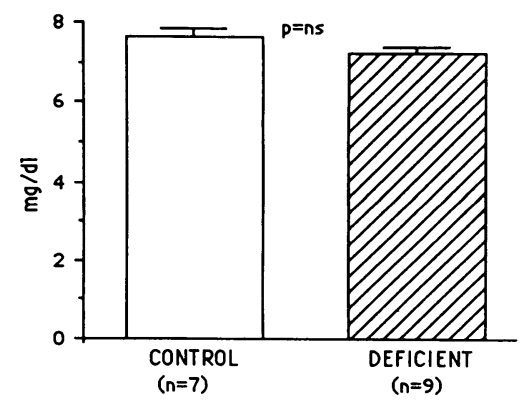

Figure 8. Plasma amino nitrogen in rats maintained on the control and deficient diets for 6-7 wk. in the animals maintained on the deficient diets. In addition, total glomerular volume and mean glomerular volume were increased in the animals subjected to vitamin $E$ and selenium deficiency. Thus, biochemical and morphometric studies demonstrate an enhanced growth response in the kidney in animals maintained on these diets.

Such enhancement of renal growth was accompanied by evidence of renal injury in the kidney in animals maintained on the deficient diets. By the eighth week after dietary assignment increased rates of protein excretion emerged in the animals on the deficient diet and this persisted for the entire duration of the study. These increased rates of urinary total protein excretion were accompanied by increased rates of excretion for IgG, albumin, and low molecular weight proteins $(<10,000 \mathrm{~mol} \mathrm{wt})$. Reduction in glomerular filtration and plasma flow rates observed at $11 \mathrm{wk}$ provided additional evidence for renal injury in the deficient animals. Finally, discernible at $9 \mathrm{wk}$ and more prominent at $14 \mathrm{wk}$, was a focal interstitial cellular infiltrate occurring in the deficient animals again demonstrating the appearance of injury at the later stage in this experimental model.

To explore the mechanisms underlying the effects of this dietary manipulation, we first examined whether metabolic effects that are known to stimulate renal growth were induced by dietary deficiency of antioxidants. First, food intake in the deficient animals tended to be less than the animals on the control diet and, thus, renal enlargement could not be ascribed to increased protein intake or increased salt intake. The features of the model are reminiscent of the kidney in hypokale-

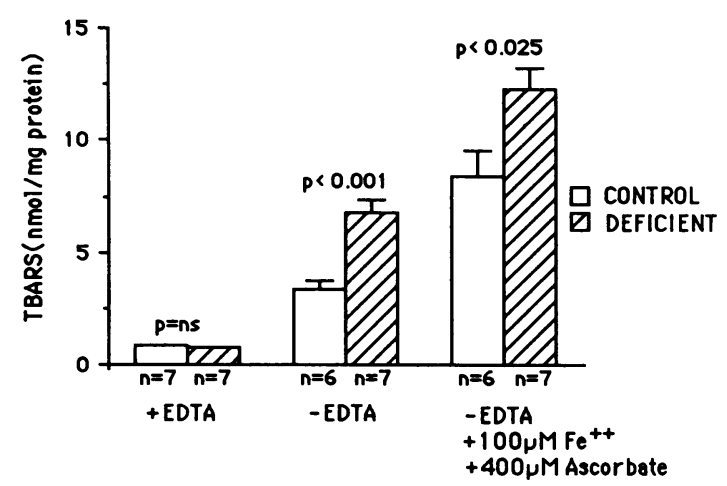

Figure 9. TBARS in control and deficient kidneys in the presence of EDTA $(+E D T A)$, in the absence of EDTA $(-E D T A)$, and in the absence of EDTA and the presence of iron and ascorbate. 

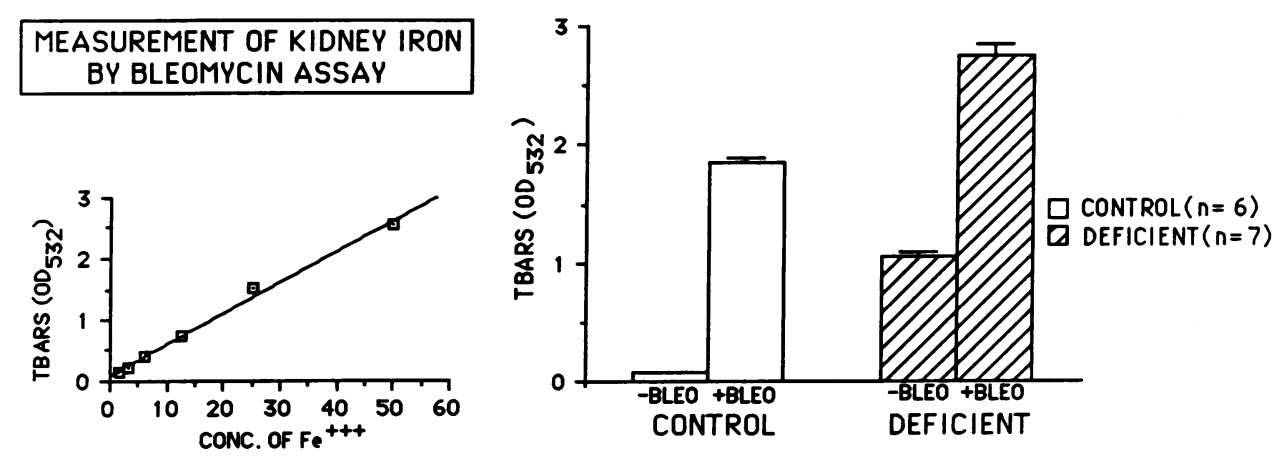

Figure 10. Measurement of kidney iron content using the bleomycin assay. The differences between the amount of TBARS generated in the presence and absence of bleomycin is a measure of the concentration of biologically reactive iron in the kidney on the respective diets. The differences in $\mathrm{OD}_{532}$ in the presence and absence of bleomycin were $1.71 \pm 0.07$ and $1.65 \pm 0.07 \mathrm{U}$ for rats on the control and deficient diets respectively, $P=$ NS. The standard curve, shown on the left, allows determination of the biologically active iron concentration. mic nephropathy $(3,4)$. However, plasma potassium concentrations were identical in the two groups and measurement of muscle potassium content revealed no significant differences in the animals maintained on the control and deficient diets. Plasma bicarbonate levels were similar and normal in both dietary groups thus providing additional evidence against hypokalemic nephropathy as well as militating against metabolic acidosis as the mechanism of growth in this experimental model. Finally, both dietary groups exhibited similar plasma glucose levels thus, arguing against diabetes as the stimulus to renal growth in the deficient animals.

That enhancement of renal growth occurred in animals maintained on a diet deficient in antioxidants, a dietary manipulation that promotes the accumulation of reactive oxygen species, is an intriguing finding especially in view of the injurious effects of reactive oxygen intermediates $(31,32)$. In this regard our findings that increased production of ammonia by the kidney antedates the appearance of renal growth in animals on the deficient diets are particularly noteworthy. The recent studies of Golchini et al. have demonstrated that increased ammonia levels per se, in concentrations achievable in physiologic and pathophysiologic states, stimulate hypertrophy of renal epithelial cells in culture. Such cellular hypertrophy induced by ammonia arises from the stimulation of protein synthesis as well as inhibition of protein degradation (30). Our data demonstrating that suppression of ammoniagenesis in the intact kidney in rats on the control.diet inhibits renal growth as measured by kidney weight coupled with similar observations in the hypokalemic nephropathy model (3) substantiate the applicability of the in vitro growth promoting effects of ammonia to in vivo circumstances. Indeed, Golchini et al. (30) have emphasized that increased ammoniagenesis occurs in several models of growth and have suggested that diverse stimuli such as increased dietary protein intake, subtotal reduction of renal mass, metabolic acidosis, and experimental diabetes mellitus utilize increased renal ammoniagenesis as a pathway for renal growth. Ammonia has also been implicated as a growth promoting stimulus in such nonrenal tissues as hepatocytes $(33,34)$, and in the hypertrophy of sea urchin eggs (35). We speculate that enlargement of the tubular epithelium and the glomerular compartment in prooxidant states arises from increased renal ammoniagenesis.

Rats on the deficient diet were supplemented with bicarbonate for $12 \mathrm{wk}$ in an attempt to observe the effect of inhibition of ammoniagenesis on the growth of the kidney. Such alkali supplementation failed to significantly suppress ammoniagenesis and the growth of the kidney, unlike the effect of such alkali therapy in rats on the control diet. Thus the increased ammonia production in the rats on the deficient diet is resistant to bicarbonate loading. Additionally, increased ammoniagenesis observed with dietary deficiency of antioxidants as employed in our studies is not due to potassium depletion, systemic acidosis, or increased delivery of amino acids to the kidney. Nor can the increased rates of ammonia production be ascribed to increased urinary flow rates per se (36) since such increased synthetic rates appeared before differences in urinary flow rates emerged between the two dietary groups. Increased urinary excretion of ammonia was not due to a more efficient trapping in the urine (37) since the $\mathrm{pH}$ was in fact higher in the animals on the deficient diet. This raises the possibility that accumulation of reactive oxygen species in the kidney may directly stimulate renal ammoniagenic pathways. An additional possibility is raised by the work of Stadtman and Berlett (38) and Berlett et al. (39), which has explored the recently described capacity of hydrogen peroxide to deaminate amino acids via a metal-ion catalyzed Fenton reaction with the generation of ammonium bicarbonate. The deficient diet employed in our study, by markedly attenuating glutathione peroxidase activity, fosters the accumulation of hydrogen peroxide normally generated in the course of renal oxidative metabolism (40). It is possible that such generation of hydrogen peroxide, through a Fenton-type reaction, leads to the deamination of amino acids thereby giving rise to ammonia.

Increased generation of ammonia may also mediate the injury that evolves in this model. Renal injury in animals on the deficient diet was tubulointerstitial in nature: a cellular infiltrate appeared in the interstitium and urinary protein excretory rates, although clearly increased in the deficient animals, remained low grade. Previously demonstrated are the marked proinflammatory effects of ammonia in such models of chronic renal injury as the subtotally nephrectomized model and the hypokalemic nephropathy model in the rat. Both of these models exhibit increased ammoniagenesis and suppression of ammoniagenesis with bicarbonate loading reduces cellular interstitial infiltration, diminishes tubular injury, reduces proteinuria, and improves renal function $(3,26)$. Ammonia exerts its inflammatory effects by directly attacking the reactive thiolester bond in the complement component $\mathrm{C} 3$ molecule thereby forming a $\mathrm{C} 3 / \mathrm{C} 5$ convertase and activating the alternative complement pathway $(3,26,41)$. Additionally, 
amidated $\mathrm{C} 3$ is a potent activator of polymorphonuclear leukocytes and monocytes (41). We suggest that the cellular infiltration and increased protein excretion that emerge in the later stages of this dietary manipulation reflect the proinflammatory effects of increased renal ammoniagenesis. The cellular interstitial infiltrate may also account for the disproportionately higher elevation in DNA content as compared to the increase in protein content in the kidney in rats maintained on the deficient diets.

We examined whether the heightened growth and injury observed in the kidney of the deficient animals was due to increased iron concentration. The rationale for pursuing this pathway as a potential mechanism is derived from the following considerations. First, cellular iron performs an essential role in myriad cellular processes and several studies point to a regulatory role of cellular iron concentration in such hyperplastic responses as the regeneration of hepatic tissue and the proliferation of bone marrow and epithelial cell lines (42). Secondly, reactive oxygen species such as superoxide and hydrogen peroxide liberate iron from proteins in which iron is stored or transported, thereby making iron available for its biologic effects $(43,44)$. Thirdly, our studies of lipid peroxidation in the control and deficient kidneys demonstrated a marked dependency on the ambient iron concentration. Fourthly, iron per se, delivered into cells by non-transferrindependent siderophores has recently been recognized to influence DNA synthesis (45). We were unable, however, to demonstrate differences in the iron concentration in the kidney of the deficient and control animals and, thus, it is unlikely that this mechanism accounted for the enhanced growth response and injury in the kidneys of the deficient animals. However, our assay further emphasizes the marked differences in antioxidant capabilities of the deficient and control animals.

We also examined whether the diet deficient in vitamin $\mathrm{E}$ and selenium induced ornithine decarboxylase activity as a potential pathway for growth in this model. Increased ornithine decarboxylase activity is observed in many states of tissue growth and regeneration (46). Additionally, there is ample recent evidence demonstrating that prooxidant states, which initiate and/or promote carcinogenesis and other forms of aberrant cell growth, involve induction of ornithine decarboxylase activity $(47,48)$. For example, phorbol myristate acetate, a particularly strong stimulus to oxidoxis and carcinogenesis, leads to the induction of ornithine decarboxylase, and such induction can be prevented by scavengers of free radicals such as superoxide dismutase and catalase (48). Additional evidence linking a prooxidant state and induction of ornithine decarboxylate activity is provided by the studies of Elsayed (49). In response to the oxidant stress of ozone, the lungs of rats rendered chronically deficient in vitamin $\mathrm{E}$ display markedly increased ornithine decarboxylase activity (49). Such findings have supported the idea that prooxidant states promote the regenerative response to injury or aberrant growth through the induction of ornithine decarboxylase (47-49). Our measurements of ornithine decarboxylase activity however failed to show increased activity in the deficient animals and thus, it is unlikely that the mechanism underlying growth and injury in this model occurs through enhanced polyamine synthesis.

Alterations in glomerular hemodynamics may be a stimulus to renal growth (1). The basis for this suggestion has arisen largely from studies in nonrenal tissues demonstrating stimulation of muscle growth in the vasculature and in cardiac tissue in response to sustained elevations in wall tension in blood vessels and the heart respectively $(50,51)$. For example, periodic increments in wall tension in isolated rabbit muscles increases the rate of muscle protein synthesis $(50)$ while pressure overload induced by aortic coarctation leads to protooncogene induction and subsequent cardiac hypertrophy in the rat (51). Since the vasoactive effects of reactive oxygen species are increasingly recognized (52), we questioned whether alterations in glomerular hemodynamics arising as a consequence of the vascular effects of the prooxidant state could be incriminated in the renal hypertrophy that subsequently emerged. Our micropuncture studies undertaken just before the enhancement of renal growth failed to reveal any significant differences in the determinants of single nephron glomerular filtration rate and, thus, it is unlikely that in this model either pressure overload or volume overload could be incriminated as a mechanism for renal growth. It should be pointed out that there were no differences in systemic blood pressure in the two dietary groups at this stage. However, in the late phase, after renal growth and injury were established, elevations in systemic arterial pressure, albeit mild, were observed in the deficient animals. Such elevation in mean arterial pressure may arise as a consequence of the renal insufficiency in the deficient animals. It is also possible that the elevated arterial pressure may arise from vasoconstrictive effects of humoral substances such as thromboxanes that are stimulated by the prooxidant state (53). Additionally, the biphasic effect of hydrogen peroxide on vasodilatory prostanoids may also be relevant. In relatively low doses, hydrogen peroxide stimulates generation of vasodilatory prostanoids, while in high doses hydrogen peroxide inhibits such generation (54). The vasoconstrictive effect observed may arise from a relative deficiency of vasodilatory prostanoids. Another potential mechanism may involve endothelial-derived relaxing factor (EDRF). The half life of EDRF is shortened by oxidant stress (55). It is possible that the prooxidant state induced by the dietary manipulation employed in our study accelerates the degradation of EDRF, thereby reducing EDRF-dependent vasodilatory tone.

The mechanisms underlying the polyuria observed in the rats on the deficient diet was not investigated in our study. We suggest that such polyuria arises, at least in part, from impairment of concentration due to tubulointerstitial disease induced by the prooxidant diet. Alterations in central mechanisms regulating water balance may also be contributory. Indeed, in hypokalemic nephropathy, a disease model also characterized by polyuria, renal growth, and renal injury, dietinduced polydipsia precedes the onset of the defect in renal concentrating ability (56). It is possible that the prooxidant diet exerts dipsogenic effects.

In summary we describe a novel model of renal growth and injury induced by dietary deficiency of antioxidants, vitamin $\mathrm{E}$ and selenium. Such renal growth occurs while growth of other organs and somatic growth are blunted. We describe the hitherto unrecognized finding of increased renal ammoniagenesis triggered by dietary deficiency of antioxidants and suggest that such renal generation of ammonia may contribute to the growth and injury that occur with this dietary manipulation. The kidney, unique in its capacity to generate ammonia, was thereby vulnerable to this dietary manipulation. Finally, that a 
prooxidant state in the kidney stimulates renal production of ammonia raises the intriguing possibility that reactive oxygen species normally generated in the course of oxidative metabolism in the intact organ may influence renal ammonia production.

\section{Acknowledgments}

We gratefully acknowledge the advice and encouragement of Dr. Thomas H. Hostetter throughout the preparation of this work. We thank Dr. Ruth Osterby and John Basgen for advice in the performance of the morphometric studies and Dr. Michael Steffes for allowing us the use of his morphometry stations. Secretarial assistance was provided by Rita Suek.

Funding for this study was provided by the National Institutes of Health grant R29-DK38767 (First Award) to Dr. Nath.

\section{References}

1. Fine, L. G. 1986. The biology of renal hypertrophy. Kidney Int. 29:619-634.

2. Hostetter, T. H., T. W. Meyer, H. G. Rennke, and B. M. Brenner. 1986. Chronic effects of dietary protein in the rat with intact and reduced renal mass. Kidney Int. 30:509-517.

3. Tolins, J. P., M. K. Hostetter, and T. H. Hostetter. 1987. Hypokalemic nephropathy in the rat: role of ammonia in chronic tubular injury. J. Clin. Invest. 79:1447-1458.

4. Toback, F. G., N. G. Ordonez, S. L. Bortz, and B. H. Spargo. 1976. Zonal changes in renal structure and phospholipid metabolism in potassium deficient rats. Lab. Invest. 34:115-124.

5. Mitch, W. E. 1984. The influence of the diet on the progression of renal insufficiency. Annu. Rev. Med. 35:249-264.

6. Fine, L. G. 1988. Preventing the progression of human renal disease: have rational therapeutic principles emerged? Kidney Int. 33:116-128.

7. Brenner, B. M., T. W. Meyer, and T. H. Hostetter. 1982. Dietary protein intake and the progressive nature of kidney disease: the role of hemodynamically mediated glomerular injury in the pathogenesis of progressive glomerular sclerosis in aging, renal ablation, and intrinsic renal disease. N. Engl. J. Med. 307:652-657.

8. Hoekstra, W. G. 1975. Biochemical function of selenium and its relation to vitamin E. Fed. Proc. 34:2083-2089.

9. Burk, R. F. 1983. Biological activity of selenium. Annu. Rev Nutr. 3:53-70.

10. McCay, P. B. 1985 . Vitamin E: interactions with free radicals and ascorbate. Annu. Rev. Nutr. 5:323-340.

11. Fischer, W. C., and P. D. Whanger. 1977. Effects of selenium deficiency on vitamin E metabolism in rats. $J$. Nutr. Sci. Vitaminol. 23:273-280.

12. Hill, K. E., and R. F. Burk. 1982. Influence of vitamin E and selenium on GSH-dependent protection against microsomal lipid peroxidation. Hepatology. 2:678.

13. Hafeman, D. G., and W. G. Hoekstra. 1977. Lipid peroxidation in vivo during vitamin $\mathrm{E}$ and selenium deficiency in the rat as monitored by ethane evolution. J. Nutr. 107:666-672.

14. Machlin, L. J., and A. Bendich. 1987. Free radical tissue damage: Protective role of antioxidant nutrients. FASEB (Fed. Am. Soc. Exp. Biol.) J. 1:441-445.

15. Nath, K. A., S. M. Kren, and T. H. Hostetter. 1986. Dietary protein restriction in established renal injury in the rat: selective role of glomerular capillary pressure in progressive glomerular dysfunction. $J$. Clin. Invest. 78:1199-1205.

16. Damadian, R. V., E. Shwayri, and N. S. Bricker. 1965. On the existence of non-urine forming nephrons in the diseased kidney of the dog. J. Lab. Clin. Med. 65:26-39.

17. Kaufman, J. M., H. J. DiMeola, N. J. Siegel, B. Lytton, M.
Kashgarian, and J. P. Hayslet. 1974. Compensatory adaptation of structure and function following progressive renal ablation. Kidney Int. 6:10-17.

18. Weibel, E. R. 1973. Stereological techniques for electron microscopic morphometry. In Principles and Techniques of Electron Microscopy, Volume 3. M. A. Hayat, editor. Van Nostrand Reinhold Co., New York. 237-296.

19. Pfaller, W., G. Gstraunthaler, and P. Kotanko. 1985. Compartments and surfaces in renal cells. In Renal Biochemistry. R. K. H. Kinne, editor. Elsevier Science Publishers, Amsterdam. 2-62.

20. Gundersen, H. J. G., and E. B. Jensen. 1987. The efficiency of systematic sampling in stereology and its prediction. J. Microsc. 147:229-263.

21. Hirose, K. R. Osterby, M. Nozawa, and H. J. G. Gundersen. 1982. Development of glomerular lesions in experimental long term diabetes in the rat. Kidney Int. 21:689-695.

22. Lawrence, R. A., and R. F. Burk. 1976. Glutathione peroxidase activity in selenium deficient rat liver. Biochem. Biophys. Res. Commun. 71:952-958.

23. Ohkawa, H., N. Ohishi, and K. Yagi. 1979. Assay for lipid peroxides in animal tissues by thiobarbituric acid reaction. Anal. Biochem. 95:351-358.

24. Gutteridge, J. M. C., D. A. Rowley, and B. Halliwell. 1981. Superoxide-dependent formation of hydroxyl radicals in the presence of iron salts. Biochem. J. 199:263-265.

25. Russell, D., and S. H. Snyder. 1968. Amine synthesis in rapidly growing tissues: ornithine decarboxylase activity in regenerating rat liver, chick embryo and various tumors. Proc. Natl. Acad. Sci. USA. 60:1420-1427.

26. Nath, K. A., M. K. Hostetter, and T. H. Hostetter. 1985. Pathophysiology of chronic tubulo-interstitial disease in rats: interactions of dietary acid load, ammonia and complement component C3. J. Clin. Invest. 76:667-675.

27. Burton, K. 1956. A study of the conditions and mechanism of the diphenylamine reaction for the colorimetric estimation of deoxyribonucleic acid. Biochem. J. 62:315-323.

28. Goodwin, J. F. 1968. The colorimetric estimation of plasma amino nitrogen with DNFB. Clin. Chem. 14:1080-1090.

29. Tannen, R. L. 1987. Effect of potassium on renal acidification and acid-base homeostasis. Semin. Nephrol. 7:263-273.

30. Golchini, K., J. Norman, R. Bohman, and I. Kurtz. 1989. Induction of hypertrophy in cultured proximal tubule cells by extracellular $\mathrm{NH}_{4} \mathrm{CI}$. J. Clin. Invest. 84:1767-1779.

31. Baud, L., and R. Ardaillou. 1986. Reactive oxygen species: production and role in the kidney. Am. J. Physiol. 251 (Renal Fluid Electrolytes 20): F765-F776.

32. Shah, S. V. 1989. Role of reactive oxygen metabolites in experimental glomerular disease. Kidney Int. 35:1093-1106.

33. Seglen, P. O. 1975. Protein degradation in isolated rat hepatocytes is inhibited by ammonia. Biochem. Biophys. Res. Commun. 66:44-52.

34. Hopgood, M. F., M. C. Clark, and F. J. Ballard. 1977. Inhibition of protein degradation in isolated rat hepatocytes. Biochem. J. 164:399-407.

35. Dube, F., and D. Epel. 1986. The relationship between intracellular $\mathrm{pH}$ and rate of protein synthesis in sea urchin eggs and the existence of a pH-independent event triggered by ammonia. Exp. Cell. Res. 162:191-204.

36. Nagami, G. T., and K. Kurokawa. 1985. Regulation of ammonia production by mouse proximal tubules perfused in vitro: effect of luminal perfusion. J. Clin. Invest. 75:844-849.

37. Tannen, R. L. 1978. Ammonia metabolism. Am. J. Physiol. 235:F265-F277.

38. Stadtman, E. R., and B. S. Berlett. 1988. Fenton chemistry revisited: amino acid oxidation. In Oxygen Radicals in Biology and Medicine. M. C. Simic, K. A. Taylor, and J. F. Ward, editors. Plenum Press, New York. 131-136. 
39. Berlett, B. S., P. B. Chock, M. B. Yim, and E. R. Stadtman 1990. Manganese (II) catalyzes the bicarbonate-dependent oxidation of amino acids by hydrogen peroxide and the amino acid facilitated dismutation of hydrogen peroxide. Proc. Natl. Acad. Sci. USA 87:389-393.

40. Guidet, B. R., and S. V. Shah. 1989. In vivo generation of hydrogen peroxide by rat kidney cortex and glomeruli. Am. J. Physiol. 256 (Renal Fluid Electolyte Physiol 25) F158-F164.

41. Hostetter, M. K., K. A. Nath, J. P. Tolins, and T. H. Hostetter. 1988. Ammonia, the kidney, and complement component C3. Proc Xth Int. Cong. Nephrol. 1:599-612.

42. Ramasarma, T. 1986. An iron-messenger system-a hypothesis. Free Radical Res. Commun. 2:153-162.

43. Biemond, P., A. J. G. Swaak, H. G. Van Eijk, and J. F. Koster. 1988. Superoxide dependent iron release from ferritin in inflammatory diseases. Free Radical Biol. Med. 4:185-198.

44. Gutteridge, J. M. C. 1986. Iron promoters of the Fenton reaction and lipid peroxidation can be released from hemoglobin by peroxides. FEBS (Fed. Eur. Biochem. Soc.) Lett. 201:291-295.

45. Laskey, J., I. Webb, H. M. Schulman, and P. Ponka. 1988. Evidence that transferrin supports cell proliferation by supplying iron for DNA synthesis. Exp. Cell. Res. 176:87-95.

46. Russell, D. H. 1985. Ornithine decarboxylase: a key regulatory enzyme in normal and neoplastic growth. Drug Metab. Rev. 16:1-88.

47. Cerutti, P. A. 1985. Prooxidant states and tumor promotion. Science (Wash. DC). 227:375-381.

48. Friedman, J., and P. Cerutti. 1983. The induction of ornithine decarboxylase by phorbol 12-myristate 13-acetate or by serum is inhibited by antioxidants. Carcinogenesis. 4:1425-1427.

49. Elsayed, N. M. 1987. Influence of vitamin E on polyamine metabolism in ozone exposed rat lungs. Arch. Biochem. Biophys. 255:392-399.

50. Palmer, R. M., P. J. Reeds, T. Atkinson, and R. H. Smith 1983. The influence of changes in tension on protein synthesis and prostaglandin release in isolated rabbit muscle. Biochem. J. 214:10111014.

51. Izumo, S., B. Nadal-Ginard, and V. Mahdavi. 1988. Protooncogene induction and reprogramming of cardiac gene expression produced by pressure overload. Proc. Natl. Acad. Sci. USA. 85:339-343.

52. Rubanyi, G. M. 1988. Vascular effects of oxygen derived free radicals. Free Radical Biol. Med. 4:107-120.

53. Sporn, P. H. S., M. Peters-Golden, and R. H. Simon. 1988. Hydrogen-peroxide-induced arachidonic acid metabolism in the rat alveolar macrophage. Am. Rev. Respir. Dis. 137:49-56.

54. Adler, S., R. A. K. Stahl, P. J. Baker, Y. P. Chen, P. M. Pritzl, and W. G. Couser. 1987. Biphasic effect of oxygen radicals on prostaglandin production by rat mesangial cells. Am. J. Physiol. 252 (Renal Fluid Electrolyte Physiol 21):F743-749.

55. Gryglewski, R. J., R. M. J. Palmer, and S. Moncada. 1986. Superoxide anion is involved in the breakdown of endothelium derived relaxing factor. Nature (Lond.). 320:454-456.

56. Berl, T., S. L. Linas, G. A. Aisenbrey, and R. J. Anderson. 1977. On the mechanism of polyuria in potassium depletion. J. Clin. Invest. 60:620-625. 